\title{
Increased Levels of Anxiety, Depression, and Secondary Trauma in Radiation Oncologists during COVID-19 Pandemic: A Preliminary Report from Turkey
}

\author{
(1) Nülifer KILIÇ DURANKUŞ, ${ }^{1}$ (i) Yasemin BÖLÜKBAŞI, ${ }^{1,2}$ (i) Yakup ALBAYRAK, ${ }^{3}$ (i) Nihan POTAS, ${ }^{4}$

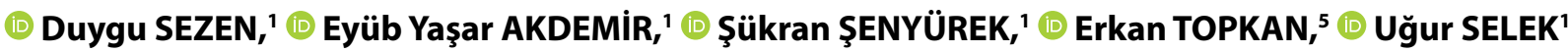

'Department of Radiation Oncology, Koc University Faculty of Medicine, Istanbul-Turkey

${ }^{2}$ Department of Radiation Oncology, University of Texas MD Anderson Cancer Center, Houston-ABD

${ }^{3}$ Department of Psychiatry, Namık Kemal University Faculty of Medicine, Tekirdağ-Turkey

${ }^{4}$ Department of Health Care Management, Hacı Bayram University Faculty of Economics and Administrative Sciences, Ankara-Turkey

${ }^{5}$ Department of Radiation Oncology, Baskent University Faculty of Medicine, Adana-Turkey

\begin{abstract}
OBJECTIVE
We surveyed the anxiety, depression, and secondary trauma levels of Turkish Radiation Oncologists related with COVID pandemics.

\section{METHODS}

An anonymous online questionnaire survey was created to evaluate levels of depression, anxiety, and secondary trauma among Turkish Radiation Oncologists. The survey included demographics and occupational status, Secondary Traumatic Stress Scale (STSSS), The Beck Depression Inventory (BDI), The Beck Anxiety Inventory (BAI), and State-Trait Anxiety Inventory (STAI).
\end{abstract}

\section{RESULTS}

Seventy-two respondents provided the power of about $91.4 \%$ for the significance level of 0.05 . The variance homogeneity was checked by the Levene test, the effect of COVID-19 on psychology is higher in the group of $>19(9.02 \pm 0.820)$, as well as the effect of social isolation $(8.02 \pm 1.622)$, the STSS scores (34.28 \pm 9.062$)$, the STAIS scores $(60.46 \pm 5.296)$, the STAIT scores $(82.21 \pm 9.298)$, the BDI scores (22.68 \pm 2.788$)$, and the BAI scores $(21.04 \pm 9.321)$. The multiple regressions to estimate BDI revealed statistically significant effects in STAIS, BAI, and STAIT. There is a significant correlation between STSS, STAIS, STAIT, BDI, BAI, the effect of COVID-19 on psychology, and the effect of social isolation.

\section{CONCLUSION}

We have established one of the first studies demonstrating the effects of COVID-19 pandemic on depression, anxiety levels, and secondary trauma on a special physician population, the Radiation Oncologists, who specifically do not directly take part in COVID19 management.

Keywords: Anxiety; depression; radiation oncology; secondary trauma.

Copyright $\odot$ 2021, Turkish Society for Radiation Oncology

\section{Introduction}

The 2019 coronavirus disease (COVID-19) epidemic that began in China spread among the world rapidly.
[1] The first COVID-19 case in Turkey was detected on March 11, 2020. By May 25, 2020, the total number of COVID-19 cases increased to 157814, and the total number of deaths was 4369.[2] The WHO announced 
this outbreak as an international health emergency.[3] Although mortality was lower, the psychological effects of the disease were more prominent.[4] The social life was designed according to pandemic conditions. Both public and health services focused on the pandemic, and as a result, various medical interventions were limited because of the ongoing pandemic process. All these measures and limitations pose a risk for future stress. Infected at the hospital and carrying the infection to home have been a separate source of stress. [5-9]

Cancer patients are considered as a high-risk group for COVID-19 pandemic, both in terms of being easily infected and having a severe infection due to immunosuppression caused by cancer and related treatments. Regarding their comorbid conditions, they tend to need intensive care unit when they are infected with COVID-19.[3] Because of this sensitivity, guidelines were published immediately due to the necessity of revision in clinical behavior by considering the benefit and risks in the approaches to the oncology patients during the pandemic.[10-14] As with all health-care professionals, these changes forced radiation oncologists to restructure their clinical work in terms of safety and effectiveness.[15,16] In this scenario, we thought that radiation oncologists could have both clinical and psychological consequences.

In terms of the fact that; whose patients were regarded as a high risk in terms of COVID-19 infection and because the COVID-19 virus blocks access to immediate cancer treatments has brought the necessity of radiation oncologists to deal with double problems. Although there have been numerous studies which investigated the psychological status of the health care professionals, [5-8] there is not any study which investigated several psychological impacts of COVID-19 pandemic on radiation oncologists.

In the present study, we aimed to investigate the anxiety, depression, and secondary trauma levels of radiation oncologists.

\section{Materials and Methods}

\section{Participants}

An anonymous survey was created to evaluate levels of depression, anxiety, and secondary trauma among Turkish Radiation Oncologists. An online questionnaire (www.SurveyMonkey.com) link including occupational and demographic data and scales were used in present study. Totally, 72 Radiation Oncologists who are members of Turkish Society for Radiation Oncology filled the survey which was delivered on $4^{\text {th }}$ April,
2020. The survey was estimated to take approximately 20 min to complete.

\section{Preliminary Data on the Participants}

We questioned participants' demographics and occupational status. Five additional questions were also presented to participants to answer (Appendix).

\section{Scales}

\section{Secondary traumatic stress scale (STSSS)}

STSSS measured the STSS symptoms. STSSS is 17 items. It measures the frequency of STSS symptoms within 17 items.[17] Accordingly, score $<28$ indicates little or no STSS; $28-37$ indicates mild STSS; $38-43$ indicates moderate STSS; 44-48 indicates high STSS, and $\geq 49$ indicates severe STSS. The STSSS was reported to be valid and reliable in the Turkish language.

\section{The beck depression inventory (BDI)}

BDI is created by Beck et al.,[18] is a self-administered questionnaire consisting of 21 multiple-choice questions. It is one of the most commonly used instruments to measure the severity of depression. The global score is an arithmetic summation of the ratings across all 21 symptoms and ranges from 0 to 63 . A higher global score indicates a higher anxiety level. BDI was reported to be valid and reliable in the Turkish language.

\section{The beck anxiety inventory (BAI)}

The BAI contains 21 items that assess the severity of clinical anxiety symptoms experienced by patients in the past month. Patients will rate each symptom on a four-point Likert scale in increasing severity, from 0 (not at all) to 3 (severe). The global score is an arithmetic summation of the ratings across all 21 symptoms and ranges from 0 to 63.[19] A higher global score indicates a higher anxiety level. BAI was validated in the Turkish language.

\section{State-trait anxiety inventory (STAI)}

The STAI, which was developed by Spielberger, is a self-report scale consisting of two sub-scales that measure state and trait anxiety (STAIS and STAIT, respectively, in this work),[20] for which scores of 20-60 can be derived. High scores indicate considerable levels of state or trait anxiety.

\section{Statistical Analysis}

Statistical analyses were done by $\mathrm{G}^{\star}$ Power version 3.1 and SPSS version 23.0. For the descriptive statistics, the central tendencies and distributions of the variables are given. According to the cut-off points of BDI, another 
variable was defined. This variable has two groups. One of them is $\leq 19$ and the other one is $>19$. For the comparison of mean, The normality assumption of parametric tests was checked with the Shapiro-Wilk test according to the BDI groups. When the assumption was satisfied, two-independent sample t-test was used to compare two groups. In non-parametric tests, Chi-square analysis was used to look for the difference between categorical variables. Depend on the normality assumption for correlation analysis; Pearson's coefficient of correlation was used. Step-wise multiple regressions were used to determine which potential dependent variables that affect the independent variables. This is the technique that also the elimination of the non-significant dependent variables. All of the assumptions of the regression were checked: The linear relationship between the independent and dependent variables, the mean of residuals is zero, normality of residuals, no multicollinearity, no autocorrelation of residuals and homoscedasticity of residuals or equal variance. 0.01 and 0.05 as a level of error probabilities (p-value) were used.

\section{Results}

In the power analysis, correlation analysis results were used. When the total sample size is 68 , the achievement of the power is $86.5 \%$ to detect an effect size of 0.3 with a significance level (alpha) of 0.05 . In the study, 72 total sample size was determined, and the power is about (symbol) $91.4 \%$ for the significance level of 0.05 .
Descriptive data are shown in Table 1. The variance homogeneity was also checked by the Levene test, and it has seen that the assumption also met. When the $\leq 19$ and $>19$ groups were compared, age, the effect of COVID-19 on psychology, the effect of social isolation, STSS, STAIS, STAIT, BDI, and BAI scores were statistically significant. The effect of COVID-19 on psychology is higher in the group of $>19(9.02 \pm 0.820)$. The effect of social isolation is higher in the group of $>19(8.02 \pm 1.622)$. The STSS scores are higher in the group of $>19$ (34.28 $\pm 9.062)$. The STAIS scores are higher in the group of $>19(60.46 \pm 5.296)$. The STAIT scores are higher in the group of $>19(82.21 \pm 9.298)$. The BDI scores are higher in the group of $>19(22.68 \pm 2.788)$. The BAI scores are higher in the group of $>19(21.04 \pm 9.321)$ (Table 2).

The correlation between STSS, STAIS, STAIT, BDI, and BAI, the effect of COVID-19 on psychology and the effect of social isolation is shown in Table 3. Overall, the effect of social isolation-the effect of COVID-19 on psychology, STAIS-the effect of COVID-19 on psychology, the effect of COVID-19 on psychology-BDI, the effect of COVID-19 on psychology-BAI, the effect of social isolation-STAIS, the effect of social isolation$\mathrm{BDI}$, and the effect of social isolation-BAI, STAIS-BDI, STAIS-BAI, and BDI-BAI have significant correlations $(\mathrm{p}<0.01)$. The correlations are positive and between 0.431 and 0.819 . On the other hand, there are no negative correlations (Table 3 ).

In the multiple regressions are tried to estimate BDI in Table 4 using the step-wise technique. According to Table 3 , in model 1 explains approximately $67.1 \%$ of the

\begin{tabular}{|c|c|c|c|c|c|c|c|}
\hline$n=72$ & Categories & $\mathbf{n}$ & $\%$ & Mean & Median & $\begin{array}{l}\text { Standard } \\
\text { deviation }\end{array}$ & Range \\
\hline \multirow[t]{2}{*}{ Gender } & Male & 17 & 24.3 & & 2.0 & & 1 \\
\hline & Female & 55 & 75.7 & & & & \\
\hline Age & & & & 41.37 & 40.0 & 8.899 & 33 \\
\hline \multirow[t]{2}{*}{ Working in Pandemic service or outpatient clinics? } & Yes & 17 & 24.3 & & 2.0 & & 1 \\
\hline & No & 55 & 75.7 & & & & \\
\hline The effect of COVID-19 on psychology & & & & 7.23 & 8.0 & 2.268 & 9 \\
\hline The effect of social isolation & & & & 6.66 & 7.0 & 2.500 & 9 \\
\hline STSS & & & & 32.91 & 30.0 & 8.813 & 35 \\
\hline STAIS & & & & 50.67 & 53.0 & 11.701 & 49 \\
\hline STAIT & & & & 80.02 & 83.0 & 12.656 & 52 \\
\hline BAI & & & & 13.39 & 11.0 & 9.992 & 34 \\
\hline $\mathrm{BDI}$ & & & & 13.41 & 15.0 & 8.607 & 26 \\
\hline \multirow[t]{2}{*}{ BDI-groups } & Cut-off point $\geq 19$ & 47 & 65.3 & & 1.00 & & 1.00 \\
\hline & Cut-off point $>19$ & 25 & 34.7 & & & & \\
\hline
\end{tabular}

STSS: Secondary traumatic stress scale; STAIS: State-trait anxiety inventory-state; STAIT: State-trait anxiety inventory-trait; BAI: Beck anxiety inventory; BDI: Beck depression inventory 
Table 2 Comparison of BDI-groups (Cutoff Point of BDI) according to the variables

\begin{tabular}{|c|c|c|c|c|c|}
\hline & \multicolumn{4}{|c|}{ BDI-groups } & \multirow[t]{3}{*}{$\mathbf{p}$} \\
\hline & \multicolumn{2}{|c|}{$\begin{array}{l}\text { Cut-off point } \\
\leq 19 n=47\end{array}$} & \multicolumn{2}{|c|}{$\begin{array}{c}\text { Cut-off point } \\
>19 n=25\end{array}$} & \\
\hline & Mean & Std. Dev. & Mean & Std. Dev. & \\
\hline Age & 42.53 & 8.134 & 39.20 & 9.905 & $0.032^{*}$ \\
\hline The effect of COVID-19 on psychology & 6.27 & 2.216 & 9.02 & 0.820 & $<0.001^{* *}$ \\
\hline The effect of social isolation & 5.94 & 2.591 & 8.02 & 1.622 & $<0.001^{* *}$ \\
\hline STSS & 30.68 & 9.920 & 34.28 & 9.062 & $0.035^{*}$ \\
\hline STAIS & 45.46 & 10.810 & 60.46 & 5.296 & $<0.001^{* *}$ \\
\hline STAIT & 75.92 & 16.641 & 82.21 & 9.298 & $0.002^{* *}$ \\
\hline BAI & 9.31 & 7.715 & 21.04 & 9.321 & $<0.001^{* *}$ \\
\hline \multicolumn{6}{|l|}{ Gender, n (\%) } \\
\hline Male & & & $12(18.8)$ & $5(5.6)$ & 0.090 \\
\hline Female & & & $34(46.5)$ & $21(29.2)$ & \\
\hline \multicolumn{6}{|c|}{ Working in Pandemic service or polyclinic?, n (\%) } \\
\hline Yes & & & $9(13.2)$ & $8(11.1)$ & 0.116 \\
\hline No & & & $38(52.1)$ & $17(23.6)$ & \\
\hline
\end{tabular}

${ }^{*} \mathrm{p}<0.05,{ }^{* *} \mathrm{p}<0.01$. BDI: Beck depression inventory; STSS: Secondary traumatic stress scale; STAIS: State-trait anxiety inventory-state; STAIT: State-trait anxiety inventory-trait; BAl: Beck anxiety inventory; Std. Dev.: Standard deviation

\section{Table 3 The correlation matrix}

The effect of COVID-19 on psychology
The effect of social isolation
STSS
STAIS
STAIT
BDI
BAI

(1)
(2)

$\begin{array}{cc}1 & \\ 0.654^{* *} & 1 \\ 0.071 & 0.027 \\ 0.661^{* *} & 0.477^{* *} \\ 0.021 & 0.051 \\ 0.592^{* *} & 0.431^{* *} \\ 0.591^{* *} & 0.495^{* *}\end{array}$

(3)

1
0.005
0.093
0.054
0.074

(4)

(5)

(6)

(7)

${ }^{*} \mathrm{p}<0.05 ;{ }^{* *} \mathrm{p}<0.01$. STSS: Secondary traumatic stress scale; STAIS: State-trait anxiety inventory-state; STAIT: State-trait anxiety inventory-trait; BDI: Beck depression inventory; BAl: Beck anxiety inventory

change in STAIS. STAIS is significant at a $1 \%$ significance level in model 1 . BDI has a positive (0.603) relationship between STAIS. It was found that this relationship was statistically significant $(\mathrm{t}=17.015, \mathrm{p}<0.01)$. The step-wise technique also gives more than one model; according to the data, this technique offers three models. The last and Model 3 explains approximately $71.1 \%$ of the change in STAIS, BAI, and STAIT. STAIS, BAI, and STAIT are statistically significant effects on BDI (Table 4).

\section{Discussion}

The whole world is affected by the COVID-19 pandemic in terms of health, economical, social and psychological manners, and prevention of the disease and the mortality risk presented by coronavirus infection. Turkey is one of the most affected countries by COVID-19 pandemics, and we have questioned radiation oncologists who are already working in a revealed unfortunate increase percentage of depression among radiation oncologists compared with the normal population. Moreover, the depression group had significantly higher scores in terms of anxiety and secondary trauma. Thus, it is inevitable to expose the negative consequences of this pandemic in Turkey as well as other countries of the world.

There have been numerous studies investigating the psychological consequences of COVID-19 pandemics on health workers.[5-9] In a recent meta-analysis which conducted the psychosocial effects of pandemics on healthcare workers showed that being younger, being more junior, being the parents of dependent children, or having an infected family member, longer quaran- 
Table 4 The results of multiple regression (Stepwise)

\begin{tabular}{|c|c|c|c|c|}
\hline Model & B & Std. Error & $\mathbf{t}$ & $\mathbf{p}$ \\
\hline \multicolumn{5}{|l|}{1} \\
\hline (Constant) & -17.116 & 1.841 & -9.296 & $<0.001^{* *}$ \\
\hline STAIS & 0.603 & 0.035 & 17.015 & $<0.001^{* *}$ \\
\hline $\mathrm{R}^{2}$ & 0.671 & & & \\
\hline $\mathrm{F}$ & 289.525 & & & \\
\hline $\mathrm{p}$ & $<0.001^{* *}$ & & & \\
\hline \multicolumn{5}{|l|}{2} \\
\hline (Constant) & -13.745 & 1.977 & -6.952 & $<0.001^{* *}$ \\
\hline STAIS & 0.482 & 0.047 & 10.311 & $<0.001^{* *}$ \\
\hline $\mathrm{BAI}$ & 0.206 & 0.055 & 3.757 & $<0.001^{* *}$ \\
\hline $\mathrm{R}^{2}$ & 0.701 & & & \\
\hline $\mathrm{F}$ & 165.190 & & & \\
\hline $\mathrm{p}$ & $<0.001^{* *}$ & & & \\
\hline \multicolumn{5}{|l|}{3} \\
\hline (Constant) & -8.725 & 2.964 & -2.944 & $0.004^{* *}$ \\
\hline STAIS & 0.494 & 0.046 & 10.648 & $<0.001^{* *}$ \\
\hline $\mathrm{BAl}$ & 0.206 & 0.054 & 3.814 & $<0.001^{* *}$ \\
\hline STAIT & 0.070 & 0.031 & 2.249 & $0.026^{*}$ \\
\hline $\mathrm{R}^{2}$ & 0.711 & & & \\
\hline $\mathrm{F}$ & 114.980 & & & \\
\hline $\mathrm{p}$ & $<0.001^{* *}$ & & & \\
\hline
\end{tabular}

${ }^{*} \mathrm{p}<0.05 ;{ }^{* *} \mathrm{p}<0.01$. STAIS: State-trait anxiety inventory-state; BAI: Beck anxiety inventory; STAIT: State-trait anxiety inventory-trait; Std. Error: Standart Error

tine, lack of practical support, and stigma also were risk factors for psychological distress in health-care professionals who worked during pandemic.[21] The COVID-19 studies included in this meta-analysis focused on healthcare workers, and there is not any study which investigated the psychological effects of COVID-19 on radiation oncologists. In our study, we found that an increased percentage of depression among radiation oncologists compared with the normal population. Moreover, the depression group had significantly higher scores in terms of anxiety and secondary trauma.

In the present study, the majority of participants did not work actively in a pandemic clinic. However, the rate of depressive status was found to be higher compared with the normal population. Second, the radiation oncologists who had scored $>19$ on BDI were found to have significantly higher scores on BAI, STAIS, STAIT, and STSSS. The STSS was taken interest during two decades to define stress acquired by helping professionals who look after traumatic patients. STSS was described as "stress resulting from helping or wanting to help a traumatized or suffering person." [22] The concept of trauma is not restricted by directly experiencing threatening assault; it also includes witnessing, observing, learning, and hearing about traumatic events.[23] Regarding our re- sults, radiation oncologists can suffer from the situation of the vulnerable status of their patients during this process. Some of the previous studies reported that working in a pandemic clinic is a severe risk factor for psychological disturbances in healthcare workers.[21] As a result, the higher percentage of depression and anxiety levels can be associated with secondary trauma in radiation oncologists beside the acceptable risk factors for developing anxiety and depression during pandemic conditions.

Our study has several limitations. The present study is based on an online survey, and we could not assess participants face to face. However, this limitation is related to the outbreak condition. Another limitation is that self-reported scales for anxiety, depression, and stress are not sufficient for making a psychiatric diagnosis. There is no specific scale for COVID-19; thus, we created simple questions about the knowledge and effects of the psychological status of COVID-19 pandemic, which can be regarded as subjective.

\section{Conclusion}

The present study is one of the first to demonstrate the effects of COVID-19 pandemic on depression, anxiety levels, and secondary trauma on a special physician population as radiation oncologists. We suggest that more studies are needed to investigate secondary trauma and its associated effects on physicians and healthcare workers during the COVID-19 pandemic.

Peer-review: Externally peer-reviewed.

Conflict of Interest: All authors declared no conflict of interest.

Ethics Committee Approval: The study was approved by the Koc University Ethics Committee (No: 2020.111. IRB1.022, Date: 25/03/2020).

Financial Support: None declared.

Authorship contributions: Concept - N.K.D., Y.B.; Design - N.K.D., Y.B., Y.A.; Supervision - D.S., S.Ş., E.Y.A., E.T., U.S.; Funding - N.K.D.; Materials - N.K.D., Ş.Ş., E.Y.A.; Data collection and/or processing - N.K.D., Y.B., Y.A.; Data analysis and/or interpretation - N.P.; Literature search - N.K.D., Y.B., Y.A.; Writing - N.K.D., Y.B.; Critical review - N.K.D., Y.B., Y.A.

\section{References}

1. Wang C, Horby PW, Hayden FG, Gao GF. A novel coronavirus outbreak of global health concern. Lancet 2020;395:470-3. 
2. Demirbilek Y, Pehlivantürk G, Özgüler ZÖ, Alp Meşe E. COVID-19 outbreak control, example of ministry of health of Turkey. Turk J Med Sci 2020;50(SI-1):489-94.

3. Cucinotta D, Vanelli M. Who declares covid-19 a pandemic. Acta Biomed 2020;91:157-60.

4. Nishiura H, Jung SM, Linton NM, Kinoshita R, Yang Y, Hayashi K, et al. The extent of transmission of novel coronavirus in wuhan, china, 2020. In: Editor, editor. The Extent of Transmission of Novel Coronavirus in Wuhan, China, 2020. Basel, Switzerland: Multidisciplinary Digital Publishing Institute; 2020.

5. Barello S, Palamenghi L, Graffigna G. The mediating role of the patient health engagement model on the relationship between patient perceived autonomy supportive healthcare climate and health literacy skills. Int J Environ Res Public Health 2020;17:1741.

6. Chew NW, Lee GK, Tan BY, Jing M, Goh Y, Ngiam NJ, et al. A multinational, multicentre study on the psychological outcomes and associated physical symptoms amongst healthcare workers during covid-19 outbreak. Brain Behav Immun 2020;88:559-65.

7. Huang Y, Zhao N. Mental health burden for the public affected by the covid-19 outbreak in china: Who will be the high-risk group? Psychol Health Med 2020;26(1):1-12.

8. Pfefferbaum B, North CS. Mental health and the covid-19 pandemic. N Engl J Med 2020;383(6):510-12.

9. Xiang Y-T, Yang Y, Li W, Zhang L, Zhang Q, Cheung T, et al. Timely mental health care for the 2019 novel coronavirus outbreak is urgently needed. Lancet Psychiatry 2020;7:228-9.

10. Romesser PB, Wu AJ, Cercek A, Smith JJ, Weiser M, Saltz L, et al. Management of locally advanced rectal cancer during the covid-19 pandemic: A necessary paradigm change at memorial sloan kettering cancer center. Adv Radiat Oncol 2020;5:687-9.

11. Wu AJ, Rimner A, Shepherd AF, Gelblum DY, Shaverdian N, Yorke E, et al. Thoracic radiation therapy during covid-19: Provisional guidelines from a comprehensive cancer center within a pandemic epicenter. Adv Radiat Oncol 2020;5:603-7.

12. Braunstein LZ, Gillespie EF, Hong L, Xu A, Bakhoum SF, Cuaron J, et al. Breast radiotherapy under covid-19 pandemic resource constraints--approaches to defer or shorten treatment from a comprehensive cancer center in the united states. Adv Radiat Oncol 2020;5:582-8.

13.Zaorsky NG, James BY, McBride SM, Dess RT, Jackson WC, Mahal BA, et al. Prostate cancer radiotherapy recommendations in response to covid-19. Adv Radiat Oncol 2020;5(4):659-65.

14. Franco P, De Rose F, De Santis MC, Pasinetti N, Lancellotta V, Meduri B, et al. Omission of postoperative radiation after breast conserving surgery: A progressive paradigm shift towards precision medicine. Clin Transl Radiat Oncol 2020;21:112.

15. Filippi A, Russi E, Magrini S, Corvò R. Covid-19 outbreak in northern italy: First practical indications for radiotherapy departments. Int J Radiat Oncol Biol Phys 2020;107:597-9.

16. Simcock R, Thomas TV, Estes C, Filippi AR, Katz MA, Pereira IJ, et al. Covid-19: Global radiation oncology's targeted response for pandemic preparedness. Clin Transl Radiat Oncol 2020;22:55-68.

17. Bride BE, Robinson MM, Yegidis B, Figley C. Development and validation of the secondary traumatic stress scale. Res Soc Work Pract 2004;14:27-35.

18. Beck W, Mendelson M, Erbaugh J. An inventory for measuring depression. Arch Gen Psych 1961;4:56171.

19. Beck AT, Epstein N, Brown G, Steer RA. An inventory for measuring clinical anxiety: Psychometric properties. J Consult Clin Psychol 1988;56:893-7.

20. Spielberger CD. Anxiety as an emotional state. In: Anxiety Current Trends and Theory. Washington, DC: American Psychological Association; 1972. p. 3-20.

21. Kisely S, Warren N, McMahon L, Dalais C, Henry I, Siskind D. Occurrence, prevention, and management of the psychological effects of emerging virus outbreaks on healthcare workers: Rapid review and metaanalysis. BMJ 2020;369:m1642.

22. Penix EA, Kim PY, Wilk JE, Adler AB. Secondary traumatic stress in deployed healthcare staff. Psychol Trauma 2019;11:1-9.

23. Diagnostic A. Statistical Manual of Mental Disorders: Dsm- ${ }^{\text {twi }}$. Arlington, VA: American Psychiatric Publishing; 2013. 


\section{Appendix}

1. Are you actively working at a pandemic outpatient clinic or service?

1. Yes

2. No

2. Do you have any medical history of mental disorders?

1. Yes

2. No

3. Please identify the level of knowledge that you have on the COVID-19 pandemic using the following scale (0: "I have no idea.", 10: "My knowledge is perfect."):

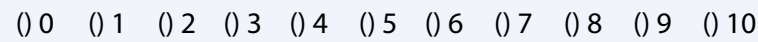

4. Do you think that the COVID-19 pandemic has affected your psychological health (0: "No", 10: "Absolutely")?

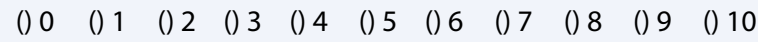

5. Do you think that the social isolation due to the pandemic has affected your psychological well-being (0: "No", 10: "Absolutely")?

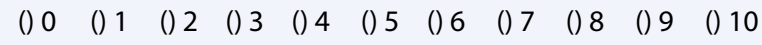

